\title{
Noise Produced By Transverse Rumble Strips: A Case Study on Rural Roadways
}

\author{
Zaiton Haron, Mohd Hanifi Othman, Khairulzan Yahya, Haryati Yaacob, \\ Mohd. Rosli Hainin, Mohd Badruddin Mohd Yusof \\ Faculty of Civil Engineering, UniversitiTeknologi Malaysia, 81310, Skudai, Johor, Malaysia
}

\begin{abstract}
Transverse roadway strips (TRS) are a common approach used by the local authorities in Malaysia for the purpose of road safety on rural roadway. However, there were complaints made by residents about the excessive noise pollution produced by TRS. The objective of this study was to evaluate the external noise produced by the application of TRS, to evaluate and to anticipate the annoyance response due to installation of TRS. The investigations were carried out through the changes of noise level indices, estimation of the annoyance response using the traffic noise index (TNI) and anticipation of resisident response anoyance. Measurements of the external noise level produced by the TRS were taken for two hours at two location with and without TRS. Results showed that TRS increased the equivalent noise level, $L_{\text {Aeqhour, }} L_{101 h o u r}$ and $L_{901 h o u r}$ by as much as $14 d B(A), 16 d B(A)$ and $9 d B(A)$ respectively. TNI values also increased as much by as $42 \%$ and exceeded the suggested value for planning purposes of $74 d B(A)$ for $3 \%$ annoyance from the social surveys. This investigation shows that TRS noise has a very strong impact on the community and this was the reason behind the complaints made by people living in study area.
\end{abstract}

Keywords: Noise pollution, Traffic noise, traffic noise index, Transverse rumble strips, traffic safety,

\section{Introduction}

Transverse roadway strips (TRS) are a common approach used by the local authority for the purpose of road safety on rural roadway. TRS aler $t$ the road user to a changing roadway environment where there is a need to exercise extraordinary caution, by generating a certain sound and vibration as a warning to vehicles driving over them. One application of TRS is at Kg Batu 30 of Pengkalan Raja, Pontian, South Malaysia which is a rural settlement area with a population living in 60 native houses. Most of the houses are built lining the road which connects the city of Pontian to the city of Skudai, Johor, Malaysia (Fig. 1). The roadway is the only route that passes through Pontian to Johor Bahru, and in this case there are several TRS installations in the region which aim to slow down the speed of vehicles passing through an area which has houses, schools and government clinics which are located less than $50 \mathrm{~m}$ away. However, the excessive noise produced by TRS has prompted local residents to lodge complaints to the district Public Works Department (PWD) and seek help for the removal of the TRS.

Noise is defined by Ouis [1] as "undesirable sound", while annoyance is a feeling of displeasure that is believed to negatively affect an individual or group of people. Many previous studies have proved that traffic noise has a significant impact on human health, both physically and psychologically [1]. Exposure to traffic noise can cause sleep disorders. Once this problem occurs, it can lead to other problems for humans, such as frustration, lowered tolerance, reduced general coping mechanisms, increased risk of accidents, fatigue and somatic complaints [2]. Boer and Schroten [3] listed the effects of traffic noise on health as including: (i) annoyance; (ii) sleep disturbance; (iii) disturbed cognitive functioning (learning and understanding); (iv) cardiovascular disease; and (v) adverse effects on mental health. However, according to Fyhri and Klaeboe [4], sensitivity is a key factor in human health problems caused by traffic noise, although they argued that health problems are caused absolutely by the direct impact of traffic noise.

According to Bendtsen et al. [5], noise from rumble strips is actually pulsating or impulse noise which is generally more annoying than continuous noise. The sounds have a similar pattern to the sound of a knocking hammer, firecrackers or an explosion. Therefore, the equivalent noise level for impulse noise has to be adjusted or increased by as much as $5 \mathrm{~dB}$ as a "penalty" to the actual noise level in order to compare it with continuous noise as concerns annoyance. Nevertheless, very few studies have been conducted into the relationship between the noise generated by TRS and annoyance to people, although some complaints from local residents to the authorities regarding this matter have been reported in the news.

The designs of the TRS in Malaysia follow the guidelines outlined in "REAM-GL8/2004 (Guidelines on Traffic Control Devices and Management), Part 4, pavement marking and delineation"[6]. Typical designs of TRS in Malaysia are illustrated in Fig. 2. Unfortunately, there is no specific pattern or profile and the TRS profiles currently installed are chosen by the Public Work Department (PWD) District Engineer or local council road engineers. In the REAM guideline the dimensions are $2250 \mathrm{~mm}$ centre to centre (L), with a width of 
$300 \mathrm{~mm}(\mathrm{~W})$ and thickness of 5-7 mm (H). According to Bendtsen et al. (2004), TRS noise level can be lowered if the $\mathrm{L}, \mathrm{W}$ and $\mathrm{H}$ are decreased. There is no specific guidance in REAM on the installation of TRS near to these sensitive areas. However, according to Van Berkel [7], TRS must not be located within $200 \mathrm{~m}$ of a residential area in order to avoid the noise problem to residents. Miska [8] has also come up with an even stricter suggestion, insisting the distance from the rumble strips to nearby residences must be $500 \mathrm{~m}$ in rural environments and $200 \mathrm{~m}$ in urban environments. The primary objectives of this investigation are (1) to evaluate the external noise produced by rumble strips installed in rural road, and (2) to evaluate and anticipate the annoyance response in the rural area due to installation of TRS. This investigation will show whether TRS noise has a strong impact on the community and consequently the reason behind the complaints made by people living in study area.

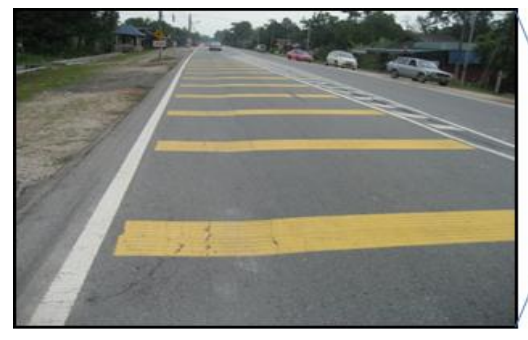

(a) Surounding location of case study

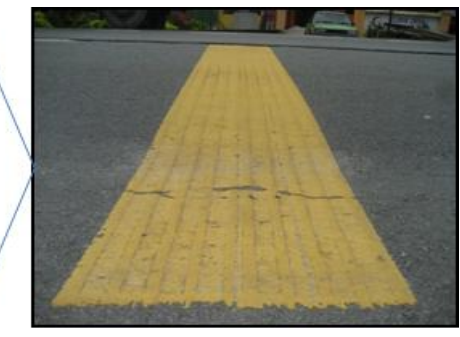

(b) TRS profile

Fig. 1. Study location

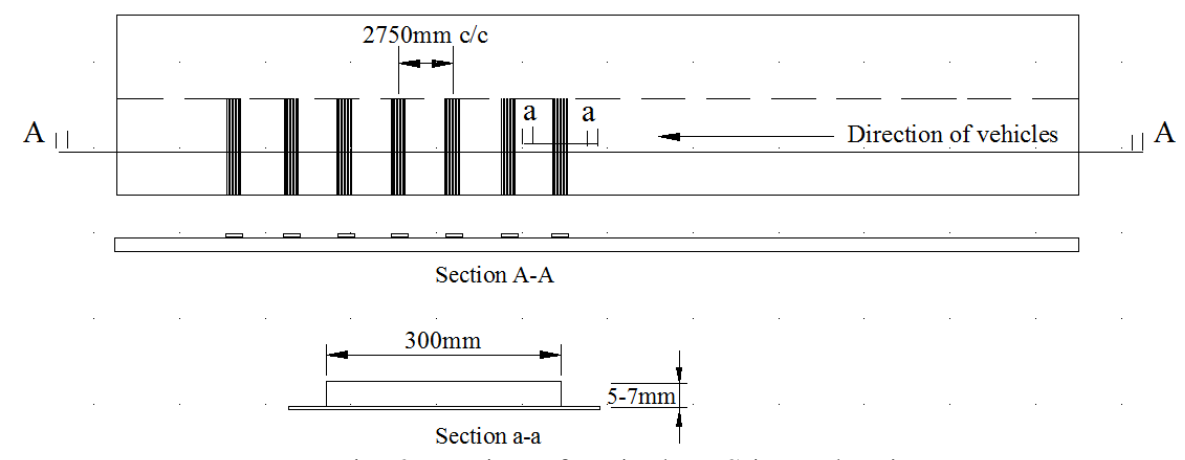

Fig. 2. Design of typical TRS in Malaysia

II. Methodology

External noise is measured by a sound level meter, which is an instrument which responds to sound in approximately the same way as the human ear and which gives reproducible measurements of sound level [9]. The equivalent continuous equal energy level ( $\mathrm{L}_{\text {Aeq }}$ ) is applied to impulse or fluctuating noise level. The $\mathrm{L}_{\mathrm{eq}}$ is defined as the constant noise level that expends the same amount of energy as a fluctuating level over the same time period [10]. The time period over which $\mathrm{L}_{\mathrm{eq}}$ is defined has to be relatively long $(1,8,12$ or $24 \mathrm{~h})$. The statistical levels $\mathrm{L}_{10}, \mathrm{~L}_{50}$, and $\mathrm{L}_{90}$ which are the noise levels that are exceeded for $10 \%, 50 \%$, and $90 \%$ of the time respectively [11] are calculated from the $1 \mathrm{hr}$ noise level, $\mathrm{L}_{\text {Aeq. }} . \mathrm{L}_{10}$ provides an indication of the upper end of the level range; while $\mathrm{L}_{90}$ constitutes the background level in the absence of nearby noise sources [12]. The general practice in Malaysia is to use the same $\mathrm{L}_{10}(18 \mathrm{~h})$ descriptor as used in the United Kingdom. This noise index can result in a reasonable outcome if it correlates well with dissatisfaction, and if it contains an accurate set of design rules for predicting the index $[9,13]$.

A Pulsar sound level meter and a sound level calibrator were used to measure noise level throughout this investigation, and the noise was given as $\mathrm{dB}(\mathrm{A})$. The noise meter was mounted on a tripod about $1.5 \mathrm{~m}$ above the ground. The sound index that was measured is the LAeq(1minute) $_{\text {for }} 1 \mathrm{hr}$ taken from 09:00 to 10:00 and 10:00 to 11:00 during week days. The external noise produced by TRS was measured at 2 locations with and without rumble strips (Fig. 3). The first location was at the middle of a group of TRS set while the second was located $300 \mathrm{~m}$ away from the first location to avoid the noise of the rumble strips (Fig. 3). The measurements were taken at two points: with TRS and without TRS. All measurements were carried out at $5 \mathrm{~m}$ from the road shoulder and carried out at the same period of time. $\mathrm{L}_{10}, \mathrm{~L}_{50}, \mathrm{~L}_{90}$ were obtained using the cumulative frequency of data reading for $1 \mathrm{hr}$. The traffic noise index (TNI) is a method used to estimate annoyance responses due to traffic noise, and is computed using the following formula $[9,14]$ :

$\mathrm{TNI}=4 \times\left(\mathrm{L}_{10}-\mathrm{L}_{90}\right)+\left(\mathrm{L}_{90}-30\right)$ 
It should be noted that a TNI of $74 \mathrm{~dB}(\mathrm{~A})$ has been reported to be associated with less than $3 \%$ annoyance in social surveys and is therefore the level suggested for planning purposes with regard to determining an optimum distance for dwellings from roadways. Also, due to the impulsive nature of TRS noise, the procedure in Annex C, Planning Guidelines for Environmental Noise Limits, Malaysia DOE [15] is utilised to estimate the perceived annoyance. In their article, Marquis-Favre and Premat [16] proposed this by introducing penalties in order to better represent the annoyance felt by the residents.

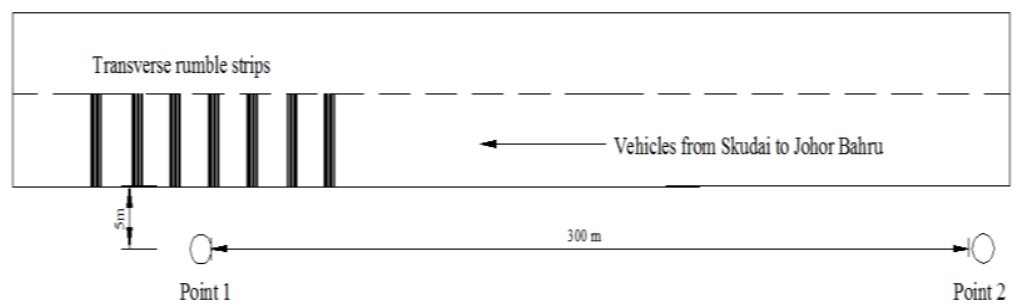

Figure 3. Measurement layout

\section{Results Of External Noise Produced By TRS}

The acquired $\mathrm{L}_{\text {Aeq }} 1$ minute traffic noise level data from 9:00 to 11:00 are shown in Fig. 4. The level induced by TRS increased compared with those without TRS. With a significance level of $95 \%$, the independent t-test showed that there was a significant difference between the noise level with and without TRS. It is also noted that noise from rumble strips is actually pulsating and has a similar pattern to the sound of a knocking hammer. The frequency distribution for $\mathrm{L}_{\text {Aeqlhr }}$ with and without TRS was constructed (Fig. 5) and the $\mathrm{L}_{10}, \mathrm{~L}_{50}$, and $\mathrm{L}_{90}$ percentile levels, with values exceeding $10 \%, 50 \%$ and $90 \%$ of the elapsed time respectively, and $\mathrm{L}_{\max }$ and $\mathrm{L}_{\min }$ standing for the maximum and minimum sound levels, were obtained. The results of the background noise level $\left(\mathrm{L}_{90}\right)$, the statistical noise level $\mathrm{L}_{10}(1 \mathrm{~h})$, and traffic noise index (TNI) with and without rumble strips for the 2 locations selected for the study in Kampung Batu 30 are given in Table 13.1. It should be noted that the background noise level corresponds to the noise level in the absence of nearby noise sources, while the statistical noise level $\mathrm{L}_{10}$ corresponds to the upper end of the noise level range [11].

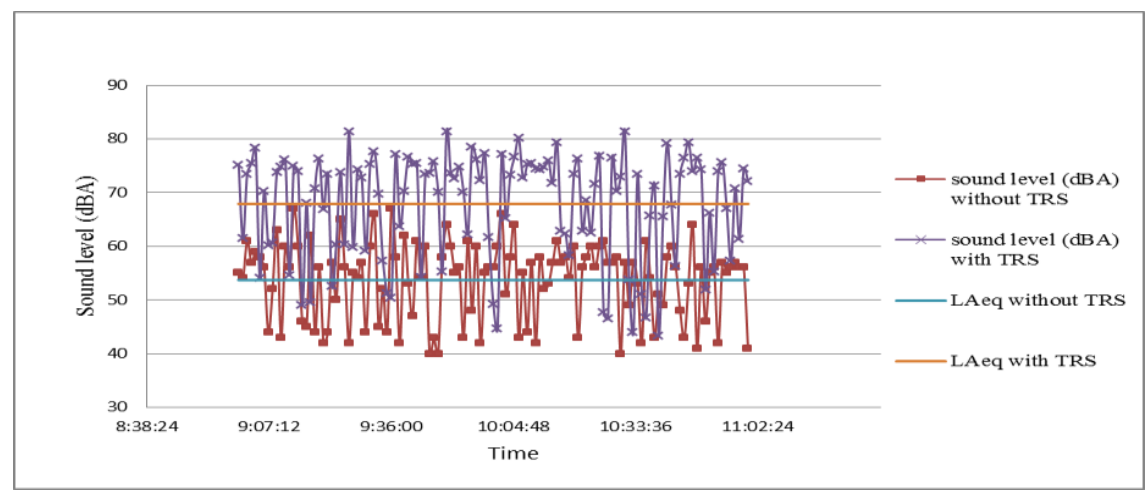

Fig. 4. Increment of noise level due to TRS

Investigation of Table 1 shows that with TRS the statistical noise level $\mathrm{L}_{10}$ has an average of $78 \mathrm{~dB}(\mathrm{~A})$ and without TRS the average was $62 \mathrm{~dB}(\mathrm{~A})$. The levels are somewhat higher in the presence of TRS, and have an average increase of $16 \mathrm{~dB}(\mathrm{~A})$ or $25 \%$ compared with the road without TRS. The increase of external noise is higher than reported by Finley and Miles [17], who found that TRS generate additional exterior noise 13\% greater than the highest noise level measured on smooth roads. Without TRS, $\mathrm{L}_{\text {Aeq }}$ were below the DOE maximum permissible limit [15]. Based on the DOE [15], a generally acceptable road traffic noise level $\mathrm{L}_{\text {day }}$ for residential areas should be less than $55 \mathrm{~dB}(\mathrm{~A})$. This is similar to the recommendation by the World Health Organization (WHO) [18] of $55 \mathrm{~dB}(\mathrm{~A})$ for outdoor areas. An area with an environmental noise level less than $55 \mathrm{~dB}(\mathrm{~A})$ is usually considered as a comfortable environment with little or no annoyance so that there will be no negative physical and mental effects on essential activities such as work, leisure and sleeping. Although $\mathrm{Kg}$ Batu 30 is a rural area, the noise levels obtained are similar to those reported for cities around the world in Jordan, Italy, Brazil, Greece and India $[9,11,19,20]$. Thus it should be noted that the noise levels with TRS are mostly considered unacceptable, resulting in the fact that voices must be raised to be understood, and phone use becomes impossible. 


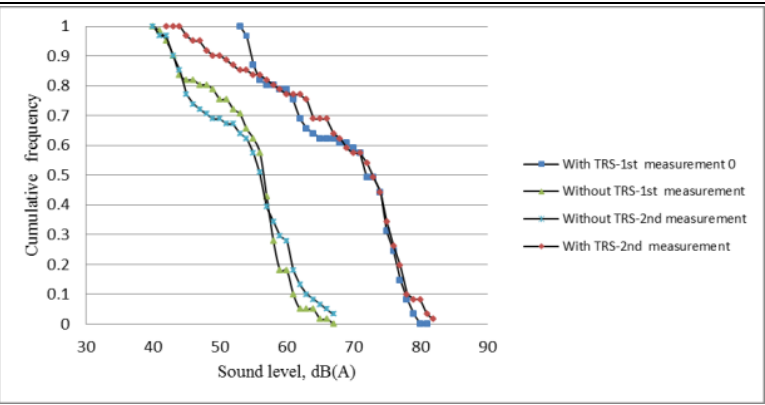

Fig. 5. Comparison of cumulative distribution for external noise due to normal traffic noise and due to the installation of TRS

Table 1. Comparison of statistical indices

\begin{tabular}{|l|c|c|c|c|c|}
\hline \multirow{2}{*}{$\mathrm{L}_{\text {index }}$} & \multicolumn{2}{|c|}{ With TRS $(\mathrm{dB}(\mathrm{A}))$} & \multicolumn{2}{|c|}{ Without TRS $(\mathrm{dB}(\mathrm{A}))$} & Differences $(\mathrm{dB}(\mathrm{A}))$ \\
\cline { 2 - 6 } & $1^{\text {st }}$ circle & $2^{\text {nd }}$ circle & $1^{\text {st }}$ circle & $2^{\text {nd }}$ circle & 15 \\
\hline $\mathrm{L}_{\max }$ & 81 & 82 & 67 & 67 & 16 \\
\hline $\mathrm{L}_{10}$ & 78 & 78 & 61 & 63 & 16 \\
\hline $\mathrm{L}_{50}$ & 72 & 73 & 56 & 57 & 9 \\
\hline $\mathrm{L}_{90}$ & 50 & 54 & 43 & 43 & 14 \\
\hline $\mathrm{L}_{\text {Aeq }}$ & 68 & 67 & 54 & 54 & \\
\hline
\end{tabular}

\section{Result Of Anticipated Resident Annoyance}

The traffic noise index (TNI) shown in Table 2 indicates that TRS increase annoyance responses due to traffic noise, resulting in a TNI of 130 with TRS and 90 without TRS. It should be noted that a TNI greater than $74 \mathrm{~dB}(\mathrm{~A})$ has been reported to be associated with less than 3\% annoyance in social surveys. Due to the impulsive nature of TRS, annoyance levels are higher than those indicated by $\mathrm{L}_{10}$ and the TNI. Table 2 shows the annoyance response due to TRS. The anticipated resident annoyance response increased from medium to very strong, which also prompted vigorous action from the residents. This is the reason why residents had complained to the district PWD seeking removal of the current TRS installation. Annoyance levels are higher than those indicated by the $\mathrm{L}_{10}$ and TNI values due to the nature of the impulsive sound produced by TRS.

Table 2. Annoyance response due to TRS

\begin{tabular}{|l|l|l|l|l|}
\hline & \multicolumn{2}{|c|}{ With TRS } & \multicolumn{2}{c|}{ Without TRS } \\
\hline TNI & 132 & 120 & 85 & 93 \\
\hline $\begin{array}{l}\text { Anticipated } \\
\text { resident } \\
\text { response } \\
\text { annoyance }\end{array}$ & Very strong impact, vigorous action & $\begin{array}{l}\text { Medium impact, widespread } \\
\text { complaint }\end{array}$ & \\
\hline
\end{tabular}

\section{Conclusion}

TRS are used as traffic safety measures and are widely installed in residential areas. The TRS profile is chosen by local authority engineers. This investigation showed that TRS increased the equivalent noise level, $\mathrm{L}_{\text {Aeq1hour, }} \mathrm{L}_{101 \text { hour }}$ and $\mathrm{L}_{901 \text { hour }}$ by as much as $14 \mathrm{~dB}(\mathrm{~A}), 16 \mathrm{~dB}(\mathrm{~A})$ and $9 \mathrm{~dB}(\mathrm{~A})$ respectively. TNI values also increased as much by as $42 \%$ and exceeded the suggested value for planning purposes of $74 \mathrm{~dB}$ (A) for $3 \%$ annoyance from the social surveys. This investigation shows that TRS noise has a very strong impact on the community and this was the reason behind the complaints made by people living in study area.

\section{Acknowledgements}

This study was funded by the Research Management Centre, Universiti Teknologi Malaysia under the Research University Grant No. Q.J130000.2522.00H62. Our deep appreciation goes to Ms. Hafisza Abd. Hamid and Mr. Ng Chee Keong from the Roads and Geotechnical Branch, Public Works Department Headquarters for all the technical information provided. Also thanks go to En. Mohd Dzurri Jumaat as a local representative in the case study area for the information provided. 


\section{REFERENCES}

[1] Ouis, D. (2001) Annoyance from road traffic noise: a review. Environmental Psychology, 101-120.

[2] Pirrera, S., Valck, E. D. \& Cluydts, R. (2010) Nocturnal road traffic noise: A review on its assessment and consequences on sleep and health. Environment International, 36, 492-498.

[3] Boer, E. D. \& Schroten, A. (2007) Traffic Noise Reduction in Europe. Delft, CE Delft.

[4] Fyhri, A. \& Klaeboe, R. (2008) Road traffic noise, sensitivity, annoyance and self-reported health - A structural equation model exercise. Environmental International, 35, 91-97.

[5] Bendtsen, H., Haberl, J., Sandberg, U. \& Watts, G. (2004) Traffic management and noise reducing pavements. Recommendations on additional noise reducing measures. SILVIA Deliverable 12, European Commission DG Tren- Growth.

[6] Road Engineering Association of Malaysia (2004). REAM-GL8/2004. Guidelines on Traffic Control and Management Devices. Malaysia, REAM.

[7] Van Berkel, C. (2009) Use of transverse rumble strips in rural areas (PW09031). Hamilton, Canada, Public Works Department

[8] Miska, E. (2009) Transverse Rumble Strips (TRS). Chief Traffic, Electrical, Highway Safety and Geometric Engineer.

[9] Jamrah, A., Al-Omari, A. \& Sharabi, R. (2006) Evaluation of Traffic Noise Pollution in Amman, Jordan. Environmental Monitoring and Assessment, 120, 499-525.

[10] Davis, M. L. and Masten, S. J. (2004) Principles of Environmental Engineering and Science. McGraw-Hill.

[11] Georgiadou, E., Kourtidis, K. and Ziomas, I. (2004) Exploratory traffic noise measurements at five main streets of Thessaloniki, Greece. Global NEST: the International Journal, 6(1), 53-61.

[12] O’Cinneide, D. (1997) Noise pollution. In: Kiely, G. (ed.) Environmental Engineering. McGraw-Hill

[13] Salter, R. J. and Hothersal, D. C. (1977) Transport and Environment. London, Granada Publishing.

[14] Langdon, F. J. and Scholes, W. E. (1968) The traffic noise index: A method of controlling noise nuisance. Building Research, Current Papers, 38168, 2-3.

[15] Department of Environment, Malaysia (2004) Planning Guidelines for Environmental Noise Limits and Control (2004). Malaysia, DOE.

[16] Marquis-Favre, C. \& Premat, E. (2005) Noise and its effect - a review on qualitative aspects of sound. Part II: Noise and annoyance. Acta Acustica United With Acustica, 91, 626-642.

[17] Finley, M. D. \& Miles, J. D. (2007) Exterior Noise Created by Vehicles Traveling over Rumble Strips. Transportation Research Board 86th Annual Meeting. Washington DC.

[18] World Health Organization (WHO). (1999) Guidelines for Community Noise. Geneva, Switzerland.

[19] Piccolo, A., Plutino, D. and Cannistraro, G. (2004) Evaluation and analysis of the environmental noise of Messina, Italy. Applied Acoustics,

[20] Zannin, P. H. T., Diniz, F. B. and Barbosa, W. A. (2002) Environmental noise pollution in the city of Curitiba, Brazil. Appl. Acoustics, 63, 315-358. 